\title{
Prosody and the Syntax of Indeterminates *
}

\author{
S.-Y. Kuroda \\ University of California, San Diego \\ and International Institute for Advanced Studies, Kyoto
}

I will extend Kitagawa and Deguchi's prosodic study of wh-question constructions to indeterminate constructions in general. I will generalize the Watanabe paradigm originally defined for wh-interrogatives to indeterminates in general. I will show that the Watanabe paradigm once lost in a narrower perspective is regained in a broader perspective.

Keywords: indeterminate, prosody, mo, additional-wh effect

\section{Introduction and background}

\subsection{The objective of the paper}

Yoshihisa Kitagawa and Masanori Deguchi have in recent work developed an analysis of the prosody associated with "focus" sentences in Japanese. ${ }^{1}$ Wh-interrogative sentences are focus sentences; applying their analysis to wh-interrogatives, Kitagawa and Deguchi account for the possible scope and scope ambiguity of wh-phrases. In particular, Kitagawa and Deguchi claim that if adequate prosody is taken into consideration we can show that wh-island effects do not exist in Japanese. As a consequence, they deny the grammaticality contrast illustrated by (1) below that Akira Watanabe claimed to exist: ${ }^{2}$

(1) a. John-wa [Mary-ga nani-o katta-kadooka] dare-ni tazuneta-no?

what bought whether who asked-Comp

'What did John ask whom whether Mary bought?'

\footnotetext{
* The first version of this paper was presented at Workshop on Prosody, Syntax and Information Structure, April 30, 2004, Bloomington, Indiana. I would like to thank an anonymous reviewer, Hiroto Hoshi and Yoshihisa Kitagawa for comments on earlier versions of the paper and related talks. This work is also a continuation of my earlier work related to the syntax of indeterminates; for giving opportunities to work on this topic, I would also like to express my gratitude to Kazuko Inoue, Mamoru Saito and Hiroto Hoshi.

${ }^{1}$ Ishihara (2003) contains material much similar to that contained in Kitagawa and Deguchi's work. For the sake of space and consistency, however, I will make references only to Kitagawa and Deguchi's work in this paper.

${ }^{2}$ The following particles and grammatical morphemes are glossed once and for all here:
}

$\begin{array}{ll}\text { wa } & \text { Topic } \\ \text { ga } & \text { Nominative } \\ \text { o } & \text { Accusative } \\ \text { ni } & \text { Dative } \\ \text { to } & \text { Quote }\end{array}$


b. ??John-wa [Mary-ga nani-o katta-kadooka] Tom-ni tazuneta-no?

what bought-whether asked-Comp

'What did John ask Tom whether Mary bought]?' (Watanabe (1992: 263))

As is well known, Japanese "wh"-words/morphemes such as dare 'who' and nani 'what' can function with quantificational force other than the interrogative. For this reason, I called those words/morphemes indeterminates. (Kuroda 1965) In earlier work I considered the analogy of the paradigm illustrated by (1) for indeterminates with quantificational force other than the interrogative.

In this paper, I will first extend the Kitagawa-Deguchi analysis of prosody to indeterminates in general. Indeterminates are divided into two classes: those with initial accent and those without accent. The former have the pitch contour $H L \ldots \ldots$ and the latter $L H \ldots \ldots$. I will call the former Falling Indeterminates (FI) and the latter Rising Indeterminates (RI). Interrogative indeterminates are all FIs. The Kitagawa-Deguchi analysis in terms of Emphatic Prosody (EPD) will be shown to extend to FLs in general directly. To account for the prosody of RI constructions, I will introduce another type of prosody, Rising Prosody (RPD). I will show that for a full account of prosody with RIs we need to recognize secondary EPD that may be superimposed on RPD.

With the analysis of prosody for RIs at hand, I will examine an extension of the Watanabe paradigm to RI indeterminates. I will show that the Watanabe type of paradigm holds for RIs if they are associated with RPD without superimposed EPD. I then claim that island effects are absent if the RPD associated with the RI construction is accompanied by secondary EPD superimposed on it.

I suggest then that a unified account of the generalized Watanabe paradigm indicates that EPD is not a component required in the syntax of the wh-question. But EPD, which is the proper prosody for independent wh-questions and also may be superimposed on default RPD prosody, can override island effects. The Watanabe paradigm is lost as an epi-phenomenon in independent wh-questions, but it is regained in embedded wh-questions and RI constructions.

In conclusion I maintain that this work demonstrates the importance of the study of prosody in syntactic analysis. After all, careful examination of prosody is indispensable even for identifying syntactic issues as such.

\subsection{The Morphology of Indeterminates}

There are five types of non-interrogative indeterminates to consider. Of these, four are associated with adnominal particles, $-m o$ for negative concord, -mo for universal quantification, demo for free choice and finally $k a$ for indefinite/existential. Let us call these adnominal particles Q-particles or Q-elements, following Nishigauchi (1990). The remaining case is indeterminates with concessive force. They are used bare, with no particle attached to them; they must however be c-commanded by the concessive subordinate conjunctive ending -temo/demo 'though' attached to a verb stem. 
Prosody and the Syntax of Indeterminates

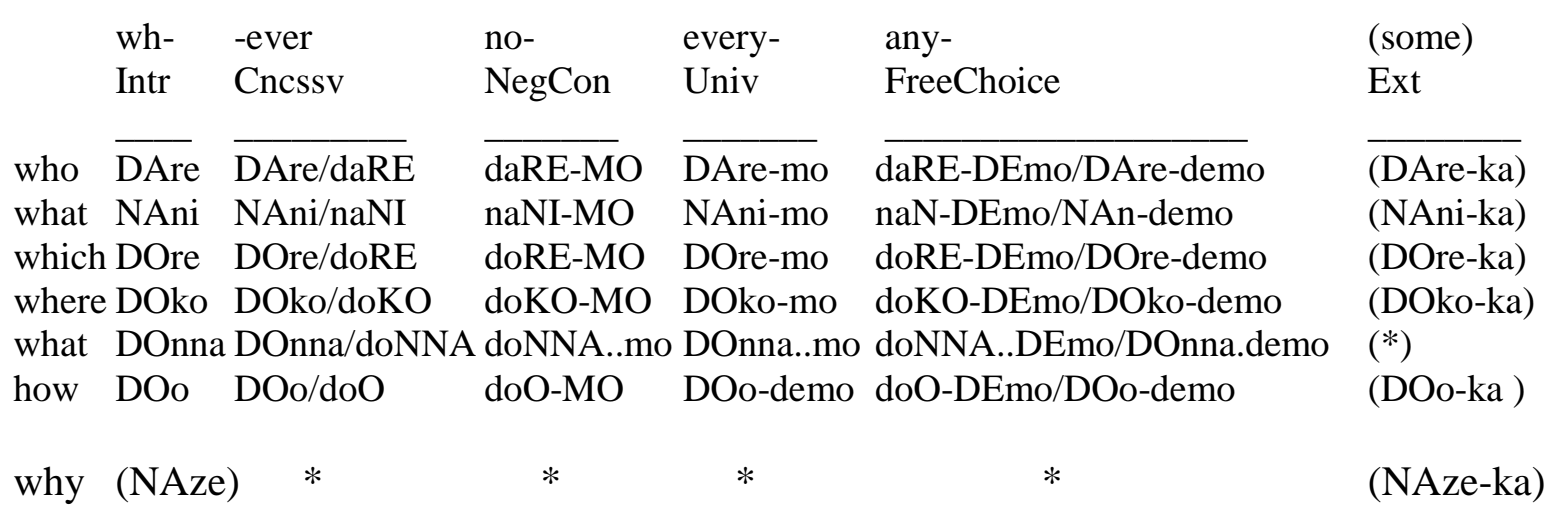

Table 1 Indeterminates

A couple of remarks are in order before we continue the main theme of this paper. First, as seen in Table 1, the particles for negative concord and universal quantification are segmentally homophonous, -mo, but the accent patterns they induce on the indeterminates they attach to are different; for example, compare daRE-MO vs. DAre-mo. ${ }^{3}$ Secondly, bare concessive indeterminates and free choice indeterminates with -demo, in my dialect, have two alternative accent patterns, apparently in free variation.

Now, more substantive remarks. I separate indefinite/existential indeterminates with $k a$, and the adjunct naze from the other indeterminates, for different reasons. First of all, $k a$ is different from the other Q-particles in that it cannot be separated from its host indeterminates. In this paper, I cannot go into full details about this fact, but we will have a glimpse of separated Q-elements shortly. I take this fact as a symptom of the fundamental difference between $k a$-attached indeterminates and the others. Secondly, NAze is an interrogative, but it does not participate in the paradigm of indeterminates as shown in the table; besides its interrogative use, it can take only the particle $k a$ and functions as indefinite meaning for some reason. To sum up, I exclude those items put in parentheses in Table 1 from indeterminates in the narrower sense we are concerned with here.

The universal DAre-mo, NAni-mo etc. tend to sound from awkward to unacceptable in various contexts to varied degrees for obscure reasons. They become quite acceptable with an affix kamo attached after -mo: DAre-mo KAmo, NAni-mo KAmo: for example, DAre-mo-ga hasitta (awkward but acceptable) vs. DAre-mo KAmo-ga hasitta (good) 'whosoever ran.'; *kare-wa NAni-mo mita (unacceptable) vs.kare-wa NAni-mo KAmo mita (good) 'he saw whatever was there'.

There are differences among indeterminates with respect to occurrence with case particles. For example, the nominative - ga co-occurs with universal DAre as seen above, but not with negative concord daRE: daRE-MO (*-ga) hasiranakatta I will not make note of these small points in the examples below.

\footnotetext{
${ }^{3}$ I assume the basic facts about the Japanese word accent; see McCawley (1968). I use capitals to indicate high pitch moras where this information is relevant.
} 


\subsection{The Syntax of indeterminates}

\subsubsection{Negative concord indeterminate mo}

A negative concord indeterminate must be c-commanded by NEG. Let us call NEG an Iprobe and -mo an I-goal. This probe/goal relationship is clause bound, which I describe as the Q-particle - mo having to be m-governed by NEG:

(2) Hanako-wa nani-mo yom-anai

anything read-not

'Hanako does not read anything'

(3) *Hanako-wa dare-mo hometa hon-o yom-anai anyone praise book read-not

*'Hanako does not read any book that anyone praised'

*Masao-wa Hanako-ga nani-mo yomu-to iw-anai

anything read say-not

*'Masao does not say that Hanako read anything'

Pied-piping, however, allows an indeterminate to be associated with NEG that ccommands but does not m-govern it:

(5) Hanako-wa dare-ga hometa hon-mo yom-anai

anyone praise book read-not

'Of anyone, Hanako does not read any book they praised' ${ }^{4}$

(6) Masao-wa Hanako-ga nani-o yomu-to-mo iw-anakatta

anything read said-not

'Of anything, Masao did not say that Hanako read them'

\subsubsection{Universal mo and free choice demo}

For universal indeterminates with the Q-particle mo and free choice indeterminates with the Q-particle demo there is no overt probe element that c-commands them:

(7) Hanako-wa nani-mo(-kamo) yomu

what (soever) read

'Hanako reads anything (whatsoever)'

\footnotetext{
${ }^{4}$ In order to be neutral about gender in English translation, I will use plural anaphor for a singular antecedent following the practice observed in the colloquial speech.
} 
(8) Hanako-wa nan-demo yomu

everything read

'Hanako reads anything'

However, we observe the same pied-piping effect as with negative concord indeterminates:

(9) Hanako-wa dare-ga hometa hon-mo yomu who praised book read

'Hanako reads any book anyone praised'

(10) Masao-wa Hanako-ga nani-o yomu-to-mo yuu read say

'Of anything Masao says that Hanako reads them'

(11) Hanako-wa dare-ga hometa hon-demo yomu praise book read Of anyone, Hanako reads books they praised'

(12) Masao-wa Hanako-ga nani-o yomu-to-demo yuu Of anything, Masao says Hanako reads them'

Hence, we hypothesize the existence of empty probe-elements that m-govern universal and free-choice Q-particles $m o$ and demo, $U N V$ and $F C H$, respectively:

(13) Hanako-wa nani-mo(-kamo) yomu-UNV

(14) Hanako-wa nan-demo yomu-FCH

(15) Hanako-wa [dare-ga hometa hon]-mo yomu-UNV

(16) Masao-wa [Hanako-ga nani-o yomu-to]-mo yuu-UNV

(17) Hanako-wa [dare-ga hometa hon]-demo yomu-FCH

(18) Masao-wa [Hanako-ga nani-o yomu-to]-demo yuu-FCH

Note that if we replace negative concord mo in (3) and (4) by universal mo or free choice demo, we get acceptable form:

(19) Hanako-wa dare-mo-ga hometa hon-o yomanai 'Hanako does not read any books that everyone praised'

(20) Masao-wa Hanako-ga nani-mo(-kamo) yomu-to iwanai 'Masao does not say Hanako reads everything'

(21) Hanako-wa dare-demo-ga hometa hon-o yomanai 'Hanako does not read books that everyone praised' 
Masao-wa Hanako-ga nan-demo yomu-to iwanai

'Masao doess not say Hanako reads everything'

But that is because they can be interpreted as forms with UNV and FCH inside embedded clauses:

(23) Hanako-wa dare-mo-ga hometa-UNV hon-o yomu

$$
\begin{aligned}
& \text { Masao-wa Hanako-ga nani-mo(-kamo) yomu-UNV to yuu } \\
& \text { Hanako-wa dare-demo-ga hometa-FCH hon-o yomu } \\
& \text { Masao-wa Hanako-ga nan-demo yomu-FCH to yuu }
\end{aligned}
$$

The same forms as (19)-(22) are unacceptable with the interpretations that are associated with the the following representations where mo and demo are not m-governed by UNV or FCH:

(28) Masao-wa Hanako-ga nani-mo(-kamo) yomu-to yuu-UNV

(29) Hanako-wa dare-demo-ga hometa hon-o yomu-FCH

$$
\text { Masao-wa Hanako-ga nan-demo yomu-to yuu-FCH }
$$

\subsubsection{Interrogative indeterminates}

An interrogative indeterminate must be c-commanded by an interrogative Comp, $k a$ in formal speech and writing, and an empty Comp accompanied by a rising intonation in informal speech. Since we are interested in prosody, I use examples with the empty interrogative Comp as much as possible. I let the question marker ? stand for the empty Comp. I use examples with $k a$ in polite speech style or in indirect questions in formal style only where it is necessary to do so in the context of discussion. However, I may use $k a$ (in place of ?) as a generic symbol for referring to the interrogative Comp in general in the text of exposition. ${ }^{5}$

\footnotetext{
${ }^{5}$ In the literature of Japanese generative linguistics, it is often the case that interrogative forms are illustrated by sentences with final particle no. Some linguists warn against this practice. The reason is that they are afraid that the no-question sentence form is not a plain question but a question form corresponding to the noda/no-de aru construction, a construction with a subtle pragmatic presupposition, somewhat similar to the English construction "it is that ..." The fact is not clear. Perhaps, in colloquial speech, the opposition between the plain form and the no da/de aru is neutralized in interrogative forms, namely, the no interrogative form is ambiguous, or vague, between the plain and the presuppositional interrogative funcitons. But even that is the case, it is prudent not to exploit the no form for testing and illustrating empirical hypotheses concerning interrogative sentences. So, I will avoid using the no question forms for examples below.
} 
Interrogative indeterminates appear bare, without any overt Q-elements that govern them. Nevertheless, the paradigm corresponding to (7), (9) and (10) holds valid for interrogative indeterminates; they do not have to be m-governed by an interrogative complementizer. In other words, the pied-piping effect is observed in this case as well:

(31) Hanako-wa nani-o yomu?

'What does Hanako read?'

(32) Hanako-wa dare-ga hometa hon-o yomu?

'Hanako reads books that who praised?'

(33) Masao-wa Hanako-ga nani-o yomu-to yuu?

'Masao says Hanako reads what?'

Two alternative analyses are conceivable. First, we may assume that there is a clausebound I-goal in this case, too; namely, we assume the existence of an empty Q-element as an I-goal corresponding to a segmentally empty I-probe, ?. Let us denote it by WH. Then we have an account of interrogative indeterminates similar to the account of universal and free choice indeterminates:

(35) Hanako-wa [dare-ga hometa hon]-WH-o yomu?

(36) Masao-wa [Hanako-ga nani-o yomu-to]-WH yuu?

According to this analysis, the interrogative indeterminate has the same syntax as the other indeterminates; it is associated with the I-probe $k a$ or ? with the intermediary of a clausebound I-goal WH. Secondly, the other alternative is to assume that there is no Q-element for interrogative indeterminates, and no I-goal for the interrogative complementizer ? or $k a$. Then, interrogative indeterminates are directly bound by its licenser, ? or $k a$, without clause-bound intermediary I-goals.

I maintain that the latter is the right alternative. There are some adjunct clauses that do not allow the pied-piping of a Q-particle. For example,

$$
\begin{gathered}
\text { Masao-wa Hanako-ga syatyoo-ni naru nara kaisya-ni todomaru } \\
\text { CEO become if company-at stay }
\end{gathered}
$$

'Masao will stay with the company if Hanako becomes CEO'

$$
\begin{aligned}
& \text { *Masao-wa dare-ga syatyoo-ni naru nara-mo kaisya-ni todomar-arani } \\
& \text { *Masao-wa dare-ga syatyoo-ni naru nara-demo kaisya-ni todomaru }
\end{aligned}
$$

The unacceptability of (38)-(39) must be syntactic and may not be attributed to semantic anomaly: if we replace the subordinate conjunction nara with to-yuu zyooken no moto de 
'under the condition that' in (37)-(39), we get wordy and somewhat awkward but acceptable sentences:

(40) Masao-wa Hanako-ga syatyoo-ni naru to-yuu zyooken-no moto-de kaisya-ni todomaru 'Masao will stay with the company under the condition that Hanako becomes CEO.'

(41) Masao-wa dare-ga syatyoo-ni naru to-yuu zyooken-no moto-de-mo kaisya-ni todomararani

'Of anyone, Masao will not stay with the company under the condition that they become CEO.'

(42) Masao-wa dare-ga syatyoo-ni naru to-yuu zyooken-no moto-de-demo kaisya-ni todomaru

'Of anyone, Masao will stay with the company under the condition that they become CEO.'

Now, if interrogative indeterminates were bound to empty Q-elements, we should expect the same acceptability pattern for interrogative indeterminates as for negative concord and free choice indeterminates as shown in (38)-(39)/(41)-(42). Instead, we have grammatical sentences both with the subordinate conjunction nara and the nominal phrase to-yuu zyooken no moto de:

(43) Masao-wa dare-ga syatyoo-ni naru nara kaisya-ni todomaru?

'Masao stays with the company if who becomes CEO?'

(44) Masao-wa dare-ga syatyoo-ni naru to-yuu zyooken-no moto-de kaisya-ni todomaru? 'Masao stay with the company under the condition that who becomes CEO?'

From these observations I conclude that interrogative bare indeterminates are not governed by an I-goal but directly bound by an interrogative Comp. ${ }^{6}$

\subsubsection{Concessive indeterminates}

A concessive indeterminate must be c-commanded by a concessive subordinate conjunction -temo/demo. Concessive indeterminates appear bare like interrogative indeterminates. Observe the following forms that correspond to (43)-(44):

(45) Masao-ga dare-ga syatyoo-ni naru nara kaisya-ni todomat-temo 'whoever it is that Masao will stay with the company if they become CEO....'

\footnotetext{
${ }^{6}$ In Old Japanese, interrogative indeterminates may either be bare or governed by the particle $\mathrm{ka}$. Bare interrogative indeterminates were bound directly by an interrogative Comp, as in Modern Japanese and they are free of island constraints. The syntax of interrogative indeterminates governed by $k a$ was much like the syntax of indeterminates associated with Q-particles in Modern Japanese; see Kuroda (forthcoming).
} 
(46) Masao-wa dare-ga syatyoo-ni naru to-yuu zyooken-no moto-de kaisya-ni todomat-temo

'whoever it is that Masao will stay with the company under the condition that they becomes CEO....'

(45) is somewhat awkward but not nearly as unacceptable as (38)-(39). I assume, then, that concessive indeterminates are, like interrogative indeterminates, directly bound by the I-probe (temo/demo) without any intermediate clause-bound Q-element.

\section{The Watanabe phenomenon lost}

Watanabe, starting from his seminal work in 1992, has taken the following paradigm as crucial evidence for wh-movement in Japanese.

(47) (Watanabe (1992: 263)

a. John-wa [ Mary-ga nani-o katta -kadooka] dare-ni tazuneta-no?

what bought whether who asked-Comp

'What did John ask whom whether Mary bought?'

b. ??John-wa [ Mary-ga nani-o katta -kadooka] Tom-ni tazuneta-no?

what bought whether asked-Comp

'What did John ask Tom whether Mary bought?'

According to Watanabe, the a-version is grammatical as wh-agreement is satisfied locally by the matrix wh-phrase dare-ni 'to whom', while the b-version is ungrammatical due to a subjacency violation.

Kitagawa and Deguchi (2003), henceforth referred to as KD, dispute this claim on the basis of their prosodic approach in syntactic analysis. They point out that by choosing types of prosody one can make the a- and b-versions either acceptable or unacceptable. On the one hand, (47a) with the intended reading must be accompanied by two independent Short EPD (Short Emphatic Prosody), and on the other, the sentence form (47b) is acceptable, with the intended reading, if it is accompanied by "Long EPD" (Long Emphatic Prosody):

(48) a. John-wa [ Mary-ga NAni-o katta-kadooka] DAre-ni tazuneta-no? what bought-whether whom asked-Comp

'What did John ask t whom Mary bought?' (KD:(33a)/(36))

b. John-wa [ Mary-ga NAni-o katta-kadooka] Tom-ni tazuneta-no? what bought-whether asked-Comp

'What did John ask Tom whether Mary bought?'

Kitagawa and Deguchi further point out that a "subjacency violation" reading is possible with an embedded multiple wh-clause such as (49), with Long EPD:

(49) John-wa [DAre-ga NAni-o katta-kadooka] Tom-ni tazuneta -no? who what bought-whether asked-Comp

'Who did John ask Tom whether bought what?

(KD:(35)) 
As Kitagawa and Deguchi emphasize, the correlation between acceptable scopes and prosody patterns is independent of whether wh-islands are involved or not; only the structure of embedding is relevant. I refer the reader to Kitagawa and Deguchi's work for details; I will explain the prosodic types they define below in section 3.1. For the moment, it suffices to take note of what Kitagawa and Deguchi conclude:

"as long as each of the [above] sentences [in question] is properly accompanied by the required prosody, they do not yield a subjacency violation, and this situation holds whether or not an "additional wh-phrase" may appear, or wherever it may appear in the sentence. Based upon this observation, we would like to point out that "additional-wh effect" for Subjacency amelioration in Japanese as a syntactic generalization is questionable..." (KD:25)

For the sake of reference, let me repeat $(47 \mathrm{a} / \mathrm{b})$ above with the judgment according to Kitagawa and Deguchi with minor adaptations:

(50) a. John-wa [Mary-ga nani-o katta -kadooka] dare-ni kiita?

what bought whether who asked

'Whom did John ask whether Mary bought what?'

b. John-wa [Mary-ga nani-o katta -kadooka] Tom-ni kiita?

what bought whether asked

'What did John ask Tom whether Mary bought?'

Let me summarize the issue. Substitute itta 'said' for kiita 'asked' and the simple quotative conjunction to for kadooka 'whether or not' in $(50 \mathrm{a} / \mathrm{b})$ and we get $(51 \mathrm{a} / \mathrm{b})$ :

(51) a. John-wa [ Mary-ga nani-o katta -to ] dare-ni itta?

what bought that who said

'Whom did John tell that Mary bought what?'

b. John-wa [ Mary-ga nani-o katta-to ] Tom-ni itta?

what-ACC that Tom-DAT said

'What did John tell Tom that Mary bought?'

Both (51a) and (51b) are grammatical; this fact is non-problematic; we have a bridge verb. $(47 \mathrm{a} / \mathrm{b})[=(50 \mathrm{a} / \mathrm{b})]$, in contrast, have the verb that might be expected to introduce a whisland. Watanabe claims that it indeed does. Watanabe judges that (47b) is ungrammatical; but he also notes that (47a) is grammatical: the wh-phrase in the matrix clause apparently eliminates the possible island effect of the wh-constituent embedded inside the island. In contrast, Kitagawa and Deguchi claim that with proper prosody $(50 \mathrm{~b})[=(47 \mathrm{~b})]$ is acceptable and that kadooka does not introduce an island. The phenomenon noticed by Watanabe turns out to be an epi-phenomenon due to improper attention to required prosody: the pair $(50 \mathrm{a} / \mathrm{b})[=(47 \mathrm{a} / \mathrm{b})]$ is as non-problematic as the pair $(51 \mathrm{a} / \mathrm{b})$. The Watanabe paradigm is lost.

Let me add here, as an anonymous reviewer of an earlier draft hinted, that the claim that the wh-complementizer kadooka does not introduce a wh-island in Japanese can be 
tested by a form simpler than (50b); we may elide the indirect object that intervenes between kadooka and the main verb:

(52) John-wa Mary-ga nani-o katta -kadooka kiita? what bought whether

'What did John ask whether Mary bought?'

To make the same point, we may use a main verb that does not select an indirect object:

(53) John-wa Mary-ga nani-o katta -kadooka oboeteiru?

what bought whether remember

"What does John remember whether Mary bought ?'

Kitagawa and Deguchi would claim that (52) as well as (53) are acceptable with proper intonation, that is, these forms are grammatical, and show that no wh-island is introduced by kadooka.

\section{Prosody of indeterminate constructions in general}

\subsection{Deguchi and Kitagawa's EPD}

I would like to investigate for the indeterminates with functional force other than the interrogative the analogues of the Watanabe paradigm illustrated by the pair $(50 \mathrm{a} / \mathrm{b})[=(47 \mathrm{a} / \mathrm{b})]$. For this purpose, I need to determine what the proper types of prosody are for indeterminate constructions in general. I will extend the idea of EPD (Emphatic Prosody) introduced by Kitagawa and Deguchi for the prosody of wh-interrogatives to the prosody of indeterminate constructions in general.

Let me at this point clarify Kitagawa and Deguchi's idea of EPD. EPD affects a string of words, which let us agree to call its domain; the domain begins with a focus at the left edge and ends at the right boundary of a clause that contains the focus as a constituent. For the purpose of our restricted study, we can assume that foci are indeterminates, that is, we assume that the domain of EPD is headed by a FI. Prosodically, two factors characterize EPD for wh-interrogatives. First, the focus (which is an interrogative whindeterminate for Kitagawa and Deguchi, and a FI in general for us) is pronounced with an emphatic accent. Secondly, the lexical accents in the domain of EPD that follow its focus is curtailed: "when one or more of lexical accents follow an emphatic accent [put on the focus], the phonetic effect of their $\mathrm{H}$ tones (of $\mathrm{H}^{*} \mathrm{~L}$ ) is significantly curtailed..." (KD:3). Let us call the part of the domain of EPD that corresponds to its focus the head, and the part that follows the focus the tail. Thus, the head of EPD is where emphatic accent is put and the tail of EPD is where lexical accents are curtailed.

In examples below, emphatic accents are indicated by bold-face and the tail of EPD, where lexical accents are curtailed, is indicated by an underline. The moras that are 
associated with high pitch are indicated by upper case letters, whether accents are curtailed or not. ${ }^{7}$

Kitagawa and Deguchi introduce subtypes of EPD. EPD is called Short EPD if its domain does not extend beyond a clause boundary. Thus, in particular, EPD of a simple sentence is necessarily and redundantly called Short EPD:

(54) DAre-ga KEeki-o TAbeta no? [= KD (14a)]

In contrast, if the focus is in a subordinate clause and the domain extends across the clause boundary into its matrix clause, EPD is called Long EPD:

(55) John-wa Mary-ga NAni-o eRAnda-ka Ima-demo siRANAi no? [=KD (17a)] what chose now even know-not Comp

'John didn't know even now what Mary chose?'

(50b), repeated here as (56), provides another example of Long EPD:

(56) John-wa Mary-ga NAni-o kaTTA-ka DOoka TOm-ni kiITA? [=(50b)]

what bought whether ask

'What did John ask Tom whether Mary bought?'

In addition, Kitagawa and Deguchi define Complex EPD: EPD is Complex EPD if there is another instance of EPD subordinated to it, that is, if its domain contains the domain of another instance of EPD. Then, the focus/head of the subordinated EPD is inside the tail of the super-ordinate EPD, and I assume, departing from Kitagawa's understanding of the term [Kitagawa: Personal communication], that the emphatic stress put on the focus of the subordinated EPD can be curtailed, that is, can to some extent be suppressed, though it cannot be totally eradicated. Complex EPD can be Short or Long, depending on whether its domain is contained in a simple clause or crosses a clause boundary and stretches over into the matrix clause:

\footnotetext{
${ }^{7}$ As a technical term, "curtailed" means that high pitch is suppressed to some degree, but not necessarily totally eliminated and leveled off. Kitagawa and Deguchi sometimes use the term "eradicated" instead of "curtailed" but their intention is to indicate the suppression of high tones in varied degrees at the lexical accents rather than total and necessary leveling of them to the base pitch level. [Kitagawa: Persomal communication] This claim can be demonstrated by the following minimal pair:
}

(i) DAre-ga kaKI-O TAbeta?

'who ate persimon?'

(ii) DAre-ga KAki-o TAbeta?

'who ate oysters?'

If lexical accents could be eliminated as a limit case of "curtailment" in this context, these two sentences would prosodically collapse and become ambiguous, but they don't. But normally curtailment tends to approach near total suppression; thus, even though I indicate lexical accent patterns by using capital letters for high pitch in curtailed parts of EPD in examples that follow, the reader is advised to keep this information in mind if he/she wants to check examples by pronouncing them. 
Long Complex EPD:

(57) John-wa [DAre-ga < who what bought make-believe

'John made Tom believe that who bought what?'

(58) John-wa [DAre-ga <NAni-o kaTTA-ka DOoka TOm-ni taZUneta no?>] [=KD (34a)] who what bought whether asked

'John made Tom believe whether who bought what?'

Short Complex EPD:

(59) John-wa [DAre-ga < NAni-o kaTTA-ka> ] Tom-ni taZUneta no? [=KD fn20 (i)] who what bought asked

'John asked Tom who bought what'

\subsection{Preliminary remarks}

Having summarized Kitagawa and Deguchi's account of prosody associated with whquestions, we are now in a position to proceed to constructions with indeterminates other than interrogatives. Let us take a look at Table 1 again. Observe the difference in the lexical accents of indeterminates. The pitch pattern of bare indeterminates with interrogative force is "falling"; it starts with a high pitched mora and continues with low pitch: DAre, NAni etc. In contrast, the pitch pattern of negative concord indeterminates is "rising"; it starts with low pitch and continues with high: daRE-MO, naNI-MO, etc. Indeterminates with concessive force and those with free choice force are doublets, with falling and rising pitch. For ease of reference, let us group indeterminates into Falling Indeterminates $(\mathrm{FI})$, with the falling pitch pattern, and Rising Indeterminates (RI), with the rising pitch pattern. To summarize:

Falling Indeterminates (FI):

DAre (intr); DAre-mo(-kamo) (unvsl); DAre-demo (FrChc); DAre..temo/demo (Cncssv)

Rising Indeterminates (RI):

daRE-MO (NgtvCncrd); daRE-DEMO (FrChc); daRE..TEmo/DEmo (Cncssv)

Concessive and Free Choice indeterminates are prosodically ambiguous.

I will first deal with the prosody associated with Falling Indeterminates. We will see that Kitagawa and Deguchi's EPD can be directly extended to FIs in general. In contrast, we will encounter some complication with the prosody associated with RIs.

\subsection{Prosody of FIs: Concessive, free choice and universal indeterminates as FIs}

Both concessive and free choice indeterminates exist in doublets, as FIs and RIs. In this section, we deal with concessive and free choice indeterminates as FIs. 
I believe that the same prosody pattern applies to universal mo indeterminates as to FI concessive and free choice indeterminates, but I will not illustrate this point. For, as noted above, universal indeterminates with mo sound one way or other awkward in many contexts. Later, however, I will claim that pied-piping in negative concord sentences provides contexts where universal mo appear rather happily.

The interrogative indeterminates are FIs; hence, we predict that the KitagawaDeguchi characterization of the prosody pattern for wh-sentences should also apply to the FI allomorphs of the concessive and the free choice indeterminates. In fact this prediction is upheld.

(60) FI Concessive:

a. Mary-ga NAni-o katTEmo

[Short EPD]

what buy

'whatever Mary buys..'

b. John-ga [Mary-ga NAni-o kaTTA-to] TOm-ni itTEmo $\square$ [Long EPD] what bought say

'whatever John tells Tom that Mary bought ...'

c. John-ga [Mary-ga NAni-o kaTTA-to] DAre-ni itTEmo $\quad$ [CmplxEPD] $\square$ what bought who say

'Whomever John tells that Mary bought whatever ...'

(61) FI Free choice:

a. Mary-ga NAn demo katta

what bought

'Mary boguth anything' EPD]

b. John-wa [Mary-ga NAni-o kaTTA-to]-demo TOm-ni yuu $\square$ [Long

[Short EPD]

what bought say

'John tells Tom that Mary bought whatever it is that she did'

c. John-wa [Mary-ga NAni-o kaTTA-to]-demo DAre-ni-demo yuu [CmplxEPD]

what bought who

'John tells whomever that Mary bought whatever it is that she did'

Free choice Indeterminates are different from interrogative and concessive indeterminates in that they are bound by Q-particle demo. In (61c) we observe pied-piping: demo is attached not directly to nani, but to the phrase Mary-ga nani o katta to. But the head of the EPD does not extend to the entire host of demo; it is limited to nani.

For FI concessives, the same paradigm for the Watanabe epi-phenomenon holds as for interrogatives:

(62) FI Concessive: The Watanabe paradigm

a John-ga [Mary-ga NAni-o kaTTA-kaDOoka] DAre-ni kiiTEmo... [CmplxEPD] $\square$ 

EPD]

b John-ga [Mary-ga NAni-o kaTTA-kaDOoka] Tom-ni kiiTEmo $\underline{\square \square} \square \square \quad[$ Long

Both forms are grammatical.

The discussion about the Watanabe (epi-)phenomenon with indeterminates that require Q-particles involves pied-piping and this matter is better first discussed with negative concord indeterminates. I assume that the later description of the Watanabe phenomenon with negative concord indeterminates also holds with free choice and universal indeterminates mutatis mutandis, but for the interest of space I have to leave the Watanabe phenomenon with free choice and universal indeterminates aside in this paper.

An additional remark is in order here. For (60c) and (61c), we have Complex EPD. According to the definition of Complex EPD, the second focus is structurally subordinated to the first focus, and its emphatic accent can be phonetically suppressed. However, for the forms segmentally identical with (60c) and (61c), the second focus may take an emphatic accent as strong as or even stronger than that put on the first focus, with a pause preceding it. In such cases, it would be fair to assume that the prosody of these forms consists of two independent instances of Short EPD, sharing the same stretch of words as their tail. I call this type of prosody Split EPD.

For that matter, forms with two instances of interrogative indeterminates are also susceptible to the same type of prosodic ambiguity. For example, consider the following multiple wh-question:

(63) dare-ga nani-o katta?

who what bought

'who bought what?'

In this form the second focus may be uttered with a suppressed accent or with a full emphatic accent, possibly with a pause between the two foci. Thus, presumably (63) may have Short Complex EPD or Split EPD:

$$
\text { [DAre-ga }<\underline{\text { NAni-o kaTTA }}>\text { ?] }
$$

[Complex Short EPD]

\section{[DAre-ga // NAni-o kaTTA?}

[Split Short EPD]

In the case of interrogative indeterminates, there seems to be a functional difference between the two prosodic alternatives: (64) is ambiguously either a multiple wh-question or a pair-list question, while (65) seems more likely to be interpreted as a pair-list question. In contrast, with concessive and free choice indeterminates, the prosodic ambiguity in question does not result in a functional difference, since the two occurrences of concessive or free choice indeterminates are scope-wise mutually free.

To sum up, we may conclude that FI indeterminates, interrogative as well as concessive and free choice (and universal as well) are prosodically equivalent. Their prosody can be accounted for in terms of Kitagawa and Deguchi's EPD. 


\subsection{Prosody of RIs}

\subsubsection{Prosody of negative concord indeterminates}

In this section I take up negative concord indeterminates as representatives of RIs and try to determine the patterns of prosody associated with RIs.

(66) Hanako-wa naNI-MO yoMAnakatta

anything read-not

'Hanako did not read anything'

(67) Hanako-wa naNI-MO kaWANAkatta

anything bought-not

'Hanako did not buy anything'

(68) daRE-MO HOn-o yoMAnakatta

anyone book read-not

'no one read books'

(69) daRE-MO HOn-o kaWANAkatta

anyone books bought-not

'no one bought books'

(66)-(69) are simple sentences that show that negative concord indeterminates dare-mo and nani-mo behave like atonic nouns. The difference between the accent patterns of the predicates in these sentences is due to the fact that yomu 'read' is an accented verb while kau 'buy' is atonic.

The intriguing part of the prosody of RIs concerns pied-piping. Consider the following sentence:

(70) Hanako-wa dare-ga kaita hon-mo yomanakatta

who wrote book rad-not

'Of anyone, Hanako did not read books that they wrote'

I take the following four forms all acceptable:

(71) a Hanako-wa daRE-GA KAITA HON-MO yoMAnakatta

b Hanako-wa daRE-GA KAITA HOn-mo yoMAnakatta

c Hanako-wa daRE-GA KAita HOn-mo yoMAnakatta

d Hanako-wa DAre-ga KAita HOn-mo yoMAnakatta

Let me first note that DAre-ga is pronounced in (71d) as a FI, contrary to the assumption that the negative concord dare is a RI. Let us leave (71d) aside for the moment. In (71a) the pied-piped noun phrase as a whole is treated as if it is an atonic prosodic word; pitch is 
raised at the second mora and stays high through the end of the noun phrase. In (71b) the word sequence dare-ga kaita is made a prosodic word; pitch is raised at the second mora and stays high through the end of the word kaita. The distinction between (71a) and (71b) is subtle in natural flow of pronunciation: in the former, pitch is lowered after $H O N M O$, while in the latter after $H O N$. The difference can be exaggerated in deliberate pronunciation where one can put a pause between kaita and hon in (71b), but not in (71a). In (71c) the lexical accents of each word is kept in tact.

Note that in (71a) the lexical accents of KAita and HOn $o$ are removed; one needs to sustain high pitch with a prolonged stretch of breadth through the end of the pied-piped phrase, which makes this form phonetically quite loaded. (71b) is less loaded, but the lexical accent of KAita is removed and high pitch must be sustained beyond a morphological word boundary. Nonetheless functionally (71b) and (71c) sound more marked or loaded than (71a); some emphasis, perhaps with contrastive effect, seems to be put on hon 'book' and kaita 'write', respectively. I would not predict that (71a) would be the most readily accepted form among (71a-c) by the native speaker judgment, if it is given for acceptability test without any natural contexts; nor would I expect (71a) to be the most likely form that one might find in a naturally collected corpus. But I take (71a) as analytically a neutral, unmarked representation of the RI prosody with pied-piping. (71b/c), I assume, are derived on the basis of (71a) with an effect of an extra-emphasis put on hon and kaita, respectively.

I propose that the idea of the Kitagawa-Deguchi analysis of prosody by means of EPD can be extended to the analysis of the RI prosody associated with negative concord RIs. Let us call the prosody associated with a RI Rising Prosody, in sort RPD. The domain of the RPD associated with a negative concord RI is by definition the part of the negative clause that starts with the RI and ends at the end of the clause. Recall that the domain of EPD consists of two parts: a head with the emphatic accent put on a FI and a tail. I assume that the domain of RPD also consists of a head and a tail.

In the case of EPD, a head is determined as the morphological word which carries a lexical accent and is headed by a FI. For the RPD associated with a negative concord RI, I assume that the head extends from the RI to the Q-particle mo and this head is the locus of the rising pitch pattern LHH...of an atonic prosodic word. The stretch of this rising pitch in effect constitutes a prosodic word. With pied-piping, the head of RPD can thus stretch over a long range, theoretically presumably unlimited. It is important to note that the lexical accents in the thus extended head of RPD are removed, rather than only suppressed to lesser or greater degree. I suggest to use the term eradicated as a technical term for this removal of lexical accents inside the head of RPD; in contrast we should reserve the term curtailed to characterize the suppression of accents such as happens inside the tail of EPD.

The tail of RPD is by definition the part of the domain that follows its head; thus, the domain of RPD is partitioned into its head and tail. I assume that the lexical accents inside the tail of the RPD are curtailed, as is the case with EPD.

What I have described above is the analytically unmarked prosody associated with a RI. (71a) exemplifies this case. Onto this prosody pattern, RPD, may additional emphatic 
prosody be imposed. This secondary prosody associated with RPD is an instance of EPD and consists of its own head and tail. Let us call the original head of the RPD its primary head and the head of this secondary EPD the secondary head of the RPD. Any morphological word inside the primary head of the RPD that follows the RI may be a secondary head. It is hon mo in (71b) and kaita in (71c). The secondary head bears emphatic lexical stress, which, however, can be attenuated as in the case of the secondary head of the Complex EPD. The domain of the secondary prosody (EPD) extends to the end of the domain of the primary prosody (RPD). The tail of the secondary prosody is the part of the domain of the primary prosody that follows the secondary head. It can be equal to the original tail of the RI prosody, as yomanakatta in (71b), or can properly contain it, as hon-o yomanakatta in (71c). The range of the primary head, that is, the range of the rising pitch LHH.. is terminated at the left of the secondary head, thus we have the shortened head of the RPD daRE-GA KAITA in (71b)and daRE-GA in (71c). The lexical accents in the tail of the secondary EPD are curtailed, as is the case with the tail of the EPD as defined by Kitagawa and Deguchi.

Let us recapitulate the Kitagawa-Deguchi Analysis Adapted for RIs (KDA-RI):

Simple RPD:

(a) RPD consists of a head and a tail.

(b) The head is headed by a RI and extends to the Q-particle mo.

(c) The lexical accents inside the head are eradicated.

(d) The lexical accents in the tail are curtailed.

RPD with secondary EPD:

(e) Secondary prosody, EPD, may be superimposed on RPD.

(f) Any morphological word in the head of RPD may be the head of secondary EPD.

(g) The domain of the secondary EPD is the part of the domain of the primary RPD to the right of the secondary head inclusive.

With this analysis in mind, I give more adequate representations of sentences in (71a-c) as follows:

(72) a. Hanako-wa daRE-GA KAITA HON-MO yoMAnakatta

b. Hanako-wa daRE-GA KAITA HOn-mo yoMAnakatta

c. Hanako-wa daRE-GA KAita HOn-mo yoMAnakatta

The head of the primary prosody (RPD), which is terminated at the position of the head of the secondary prosody, if there is one as in $(72 \mathrm{~b} / \mathrm{c})$, is indicated by italic. The head of the secondary prosody (EPD) is indicated by bold-face; it is assumed to bear a suppressed emphatic accent. The tail of the primary or of the secondary prosody, where lexical accents are curtailed, is indicated by underline. 
Before testing the proposed analysis with more examples, let me at this point return to $(71 \mathrm{~d})$, which previously I put aside. I presume that the lexical accents that follow DAre$g a$ in (71d) are curtailed in natural pronunciation. I assume that we have here an instance of EPD. In conformity with the improved transcriptions given in (72a-c), let me also replace (71d) by the following:

\section{(72) d. Hanako-wa DAre-ga KAita HOn-mo yoMAnakatta}

It might be tempting to assume that the prosodic pattern is accounted for as a limit case where the secondary EPD prosody is superimposed on the entire domain of the primary RID, thus completely overriding the primary prosody. The suggestion is that the negative concord rising $d a R E$ is prosodically, but not functionally, converted to falling DAre. But I argue against this hypothesis.

Recall that negative concord indeterminates are segmentally, though not prosodically, homophonous with universal indeterminates. Thus, prima facie the DAre in (72d) can be an instance of universal DAre. And I claim indeed that is the case. If so, negation must take narrower scope than DAre for the intended interpretation. We can in fact show that negative concord daRE takes narrow scope but DAre in forms like (72d) takes wide scope. On the ground of this fact, I maintain that DAre in (72d) is universal quantifier, not a prosodically aberrant occurrence of the negative concord indeterminate. Compare the following forms; they differ only in prosody:

\section{(73) a. Hanako-wa daRE-GA KAITA HON MO kaTTE yoMAnakatta \\ b. Hanako-wa DAre-ga KAita HOn-mo kaTTE yoMAnakatta \\ who wrote book buy read-not}

With katte yomanakatta uttered naturally without a pause, both (73a) and (73b) can mean 'For books written by anyone, Hanako did not buy and read them'. We can put a pause between katte and yomanakatta in (73b) and mean 'for books written by anyone, Hanako bought them but did not read them'. In contrast, we cannot put a pause between katte and yomanakatta in (73a). We can account for this contrast, if we assume that daRE in (73a) is semantically associated with negation (and interpreted as negative concord indeterminate), while Dare in (73b) is associated with $m o$ and interpreted as a universal quantifier

Among the four alternatives given in (71a-d), (71d) is likely to be the most, and (71a) the least, readily and easily accepted one by the native judgment if these forms are given for acceptability judgment without any particular pragmatic context. This fact needs an account. Functionally, (71a) is unmarked in comparison with (71b) and (71c), since the latter two bear an added factor of emphasis, entailing the existence of a certain pragmatic presupposition. For the intended interpretation, neither the negative concord as in (71a) nor the universal quantifier as in (71d) should have functional advantage in the given syntactic context. Hence, from the functional perspective, (71a) and (71d) are less loaded than (71b) and (71c) and should be at the same level of acceptability. However, in the prosodic perspective, (71a) is very loaded; it demands unnaturally sustained articulatory tension. We can expect that this tension contributes to making its acceptability degree low. 
Let us now test the above analysis with a couple of other sentences. I will first substitute eRAnda 'chose' for the verb KAita 'write', the penultimate accented TAko 'octopus' and the ultimate accented niKU 'meat' for the noun HOn 'book', and taBEnakatta 'did not eat' for yoMAnakatta 'did not read'. We confirm the same patterns of possible prosodic patterns as above:

(74) a. Masao-wa daRE-GA ERANDA TAKO-MO taBEnakatta

b. Masao-wa daRE-GA ERANDA TAko-mo taBEnakatta

c. Masao-wa daRE-GA eRAnda TAko-mo taBEnakatta

d. Masao-wa DAre-ga eRAnda TAko-mo taBEnakatta

'Of anybody, Masao did not eat any octopus that they chose'

(75) a. Masao-wa daRE-GA ERANDA NIKU-MO taBEnakatta

b. Masao-wa daRE-GA ERANDA niKU-mo taBEnakatta

c. Masao-wa daRE-GA eRAnda niKU-mo taBEnakatta

d. Masao-wa DAre-ga eRAnda niKU-mo taBEnakatta

'Of anybody, Masao did not eat any meat that they chose'

If we substitute the atonic $i K A$ 'squid' for the ultimate accented $n i K U$, we get the following paradigm:

(76) a. Masao-wa daRE-GA ERANDA IKA-MO taBEnakatta

b. Masao-wa daRE-GA ERANDA iKA-MO taBEnakatta

c. Masao-wa daRE-GA eRAnda iKA-MO taBEnakatta

d. Masao-wa DAre-ga eRAnda iKA-MO taBEnakatta

'Of anybody, Masao did not eat any squid that they chose'

Note the difference between (75b) and (76b), a subtle difference both prosodically and semantico-functionally. The particle $m o$ is enclitic: it preserves the accent of the word it attaches to. The noun $n i K U$ has a ultimate accent and hence when $m o$ is attached to it, we get the accented niKU-mo. In contrast, $i K A$ is atonic and when the enclitic mo is attached to it, we get atonic $i K A-M O$, not $i K A-m o$. Note, further, that $I K A-M O$ in (76a) is part of the elongated prosodic word with a rising pitch pattern daRE-GA ERANDA IKA-MO; in contrast, $i K A-M O$ in $(76 \mathrm{~b}-\mathrm{d})$ is an instance of an atonic morphological word. The word $i K A-M O$ in (76b) is supposedly the head of the secondary prosody, EPD, but due to the fact that $i k a$ is an atonic noun the semantico-functional emphasis of the secondary prosody must be borne by this atonic phrase. Prosodically, $i K A-M O$ must be emphatic, but how prosodic emphasis is actualized in an atonic phrase is a question that I am not in a position to speculate and have to leave open for experimental inquiries. In contrast to $\boldsymbol{i} \boldsymbol{K} \boldsymbol{A}-\boldsymbol{M O}$ in (76b), $i K A-M O$ in (76c) is supposed not to be prosodically emphatic. The experimental comparison, if possible, between (76b) and (76c) should be instructive for finding the phonetic and functional character of the paradigm we are concerned with here. But the contrast in question may be too subtle to be tested experimentally.

If an atonic verb, for example, tuTTA 'fished/caught' substitutes for the accented verb eRAnada 'choose', a situation similar to (76b) obtains this time with the c-alternative: 
(77) a. Masao-wa daRE-GA TUTTA IKA-MO taBEnakatta

b. Masao-wa daRE-GA TUTTA iKA-MO taBEnakatta

c. Masao-wa daRE-GA tuTTA iKA-MO taBEnakatta

d. Masao-wa DAre-ga tuTTA iKA-MO taBEnakatta

Here, too, semantico-functional emphasis must be borne by an atonic phrase, tuTTA in $(77 \mathrm{c})$.

I conclude that these examples substantiate the analysis of the RI prosody worked out with (71a-d) $[=(72 \mathrm{a}-\mathrm{d})]$ above.

\subsubsection{Prosody of free choice and concessive RI indeterminates}

To recall, free choice and concessive indeterminates are prosodically ambiguous, either FIs or RIs. The Kitagawa-Deguchi Analysis Extended for RIs, which was worked out above with negative concord indeterminates, also accounts for the prosody of RI free choice and concessive RI indeterminates, as shown below. A couple of remarks may be in order. First, for concessive indeterminates, since they are bare, the right edge of the head of RPD is not overtly marked by a Q-particle. Secondly, the indeterminates in the d-alternatives below are the FI variants of free choice and concessive indeterminates.

(78) a. Masao-ga daRE-GA ERANDA TAKO-O TAbetemo

b. Masao-ga daRE-GA ERANDA TAko-o TAbetemo

c. Masao-ga daRE-GA eRAnda TAko-o TAbetemo

d. Masao-ga DAre-ga eRAnda TAko-o TAbetemo

(79) a. Masao-ga daRE-GA ERANDA NIKU-O TAbetemo

b. Masao-ga daRE-GA ERANDA niKU-o TAbetemo

c. Masao-ga daRE-GA eRAnda niKU-o TAbetemo

d. Masao-ga DAre-ga eRAnda niKU-o TAbetemo

(80) a. Masao-ga daRE-GA ERANDA IKA-O TAbetemo

b. Masao-ga daRE-GA ERANDA IKA-O TAbetemo

c. Masao-ga daRE-GA eRAnda iKA-O TAbetemo

d. Masao-ga DAre-ga eRAnda iKA-O TAbetemo

(81) a. Masao-wa daRE-GA ERANDA TAKO-DEMO TAbeta

b. Masao-wa daRE-GA ERANDA TAko-demo TAbeta

c. Masao-wa daRE-GA eRAnda TAko-demo TAbeta

d. Masao-wa DAre-ga eRAnda TAko-demo TAbeta

(82) a. Masao-wa daRE-GA ERANDA NIKU-DEMO TAbeta

b. Masao-wa daRE-GA ERANDA niKU-demo TAbeta

c. Masao-wa daRE-GA eRAnda niKU-demo TAbeta

d. Masao-wa DAre-ga eRAnda niKU-demo TAbeta 
(83) a. Masao-wa daRE-GA ERANDA IKA-DEMO TAbeta

b. Masao-wa daRE-GA ERANDA iKA-DEMO TAbeta

c. Masao-wa daRE-GA eRAnda iKA-DEMO TAbeta

d. Masao-wa DAre-ga eRAnda iKA-DEMO TAbeta

\section{Generalized Watanabe phenomena}

With the prosody associated with both FIs and RIs having been worked out, we are now prepared to deal with the Watanabe paradigms for indeterminates in general. We are interested in the paradigm illustrated by $(47 \mathrm{a} / \mathrm{b})$, or by the amended $(50 \mathrm{a} / \mathrm{b})$, but I now wish to replace the interrogative force of indeterminates by those with other functional force.

\subsection{Generalized Watanabe phenomena with negative concord indeterminates}

\subsubsection{Subordinate clauses with quotative to}

Let us first consider the non-problematic pair with a bridge verb. We replace itta 'said' by its negative iwanakat-ta 'did not say' in (50a/b) and interpret the indeterminates nani and dare in them with negative concord instead of interrogative force. To begin with, dare must be bound by mo; we must have dare-ni-mo instead of dare-ni. Next, the syntax of indeterminates described in section 1.3 requires that I-probe NEG m-governs I-goal mo attached to the to-phrase, pied-piping the indeterminate nani in it. We get the following forms:

(84) a. John-wa [Mary-ga nani-o katta-to]-mo dare ni-mo iwanakatta anything bought that anyone say-neg-past

Wohn did not say to anyone [that Mary bought anything]'

'Of anything, John did not say to anyone [that Mary bought them]'

b. John-wa [Mary-ga nani-o katta-to]-mo Tom-ni iwanakatta anything that Tom say-neg-past

\$ohn did not say to Tom that Mary bought anything'

'Of anything, John did not say to Tom that Mary bought them'

In each example, I inserted a line marked with between a gloss and an English translation. indicates that an English form is more or less a word-by-word rendition and not only may not be a grammatical English form but also may not accurately correspond to the intended meaning of the Japanese example. Thus, for example, in (84a) both nani-o and dare-ni-mo are negative concord terms; this fact is not reflected in the marked form in (84a). In contrast, the English sentences given between a pair of quotation marks as translations, syntactically awkward though they are, are intended to be accurate representations of the intended meanings of the Japanese original. Incidentally, them in these English translations is understood as coreferential with anything, following the convention already introduced. I continue to use forms below when advisable in order for the reader to get a feel on the structure of Japanese forms that may not be obvious from English translations. 
Both $(84 \mathrm{a} / \mathrm{b})$ are grammatical, as expected. Indeed, all the prosodic patterns predicted by the KDA-RI are acceptable. In order to display those patterns, we first need to give underlying representations of $(84 \mathrm{a} / \mathrm{b})$ that contain morphological information sufficient for the derivation of the lexical accents in the sentences in question. ${ }^{8}$

(85) a. John-wa Mary-ga \# nani >o'\# kaw >ta' \#/>to'>mo \# dare >ni'>mo\# iw $>$ ana'kat $>$ ta'

b. John-wa Mary-ga \# nani>o'\# kaw>ta' \#/>to'>mo \# To'm>ni' \# iw>ana'kat>ta'

Due to prosodic ambiguity of $t o^{\prime},(85 \mathrm{a} / \mathrm{b})$ each contain two representations, which I separate below:

(86) a1 John-wa Mary-ga \# nani>o' \# kaw $>$ ta' $>$ to'>mo \# dare $>$ ni'>mo\# iw $>$ ana'kat $>$ ta' a2 John-wa Mary-ga \# nani>o' \# kaw $>$ ta' \#to'>mo \# dare $>$ ni' $>$ mo\# iw $>$ ana'kat $>$ ta' b1 John-wa Mary-ga \# nani >o' \# kaw $>$ ta' $>$ to'>mo \# To'm $>$ ni' \# iw $>$ ana'kat $>$ ta' b2 John-wa Mary-ga \# nani>o' \# kaw>ta' \#to'>mo \# To'm>ni' \# iw>ana'kat>ta'

From these representations, we can derive the lexical accents in (86a/b) actualized as shown below:

(87) a1 John-wa Mary-ga \# naNI-O \# kaTTA-to-mo \# daRE NI-MO \# iWANAkatta a2 John-wa Mary-ga \# naNI-O \# kaTTA \# TO-mo \# daRE-NI-MO \# iWANAkatta b1 John-wa Mary-ga \# naNI-O \# kaTTA-to-mo \# Tom-ni \# iWANAkatta b2 John-wa Mary-ga \# naNI-O \# kaTTA \# TO-mo \# Tom-ni \# iWANAkatta

Now, (84a) contains two RIs, nani and dare. Recall that a sentence form that contains two interrogative indeterminates, or two FIs in general, are prosodically ambiguous; it may have Complex EPD or Split EPD. It seems that the same situation obtains for sentences that contain two negative concord indeterminates like (84a); it may have Complex RPD or Split RPD. The prosodic ambiguity is probably correlated with functional ambiguity similar to the ambiguity we have associated with double FI sentences, but more research is needed to confirm this point. In the following presentation, I disregard this possible ambiguity and present examples in the forms with Split RPD.

We can apply KDA-RI to the two RIs in (84a) independently. Let us first keep dare-ni-mo invariant as a RPD head daRE-NI-MO and apply KDA-RI to nani-o. We derive three and four forms from (87a1) and (87a2), respectively:

(88) 1 John-wa Mary-ga naNI-O KATTA-TO-MO daRE-NI-MO iWANAkatta

2 John-wa Mary-ga naNI-O kaTTA-to-mo daRE-NI-MO iWANAkatta

3 John-wa Mary-ga NAni-o kaTTA-to-mo daRE-NI-MO iWANAkatta

\footnotetext{
${ }^{8}$ I use the following notations and conventions. High pitch in speech forms is indicated by capital letters, low pitch by lower case letters. The quotation mark ' indicates the place of accent in underlying representations. It is put after the vowel of the "accented" mora, that is, the mora after which pitch is to shift from high to low. For example, $h o^{\prime} n$ is pronounced as HOn. The "larger than" sign > indicates that the morpheme that follows it is enclitic, that is, it loses its accent if preceded by an accented morpheme. \#/> indicates prosodic ambiguity between a possible word boundary and an enclitic morpheme boundary.
} 
(89) 1 John-wa Mary-ga naNI-O KATTA TO-MO daRE-NI-MO iWANAkatta

2 John-wa Mary-ga naNI-O KATTA TO-mo daRE-NI-MO iWANAkatta

3 John-wa Mary-ga naNI-O kaTTA TO-mo daRE-NI-MO iWANAkatta

4 John-wa Mary-ga NAni-o kaTTA TO-mo daRE-NI-MO iWANAkatta

(88.1) and (89.1) are identical and associated with RPD without secondary EPD. (88.2) and (89.2/3) are associated with RPD with secondary EPD. (88.3) and (89.4) contain nani interpreted as a universal quantifier and are associated with EPD.

The prosodic patterns for (84b) can be obtained by replacing daRE NI-MO in (88)(89) by Tom-ni. We get Long RPD in (90.1/2) and (91.1/2/3), and EPD in (90.3) and (91.4).

(90) 1 John-wa Mary-ga naNI-O KATTA-TO-MO TOm-ni iWANAkatta

2 John-wa Mary-ga naNI-O kaTTA-to-mo TOm-ni iWANAkatta

3 John-wa Mary-ga NAni-o kaTTA-to-mo TOm-ni iWANAkatta

(91) 1 John-wa Mary-ga naNI-O KATTA TO-MO TOm-ni iWANAkatta

2 John-wa Mary-ga naNI-O KATTA TO-mo TOm-ni iWANAkatta

3 John-wa Mary-ga naNI-O kaTTA TO-mo TOm-ni iWANAkatta

4 John-wa Mary-ga NAni-o kaTTA TO-mo TOm-ni iWANAkatta

Prosodically, the differences between some of these forms are quite subtle. For example, consider (91.2/3). They can certainly be distinguished by careful pronunciations; there is a prosodic word boundary between nani-o and katta to-mo in (91.3), but not in (91.2), and as a consequence a deliberate pause or pitch lowering at the beginning of kaTTA TO-mo is possible in (91.3), but not in (91.2). But if either of them is uttered with the natural flow of pronunciation, it would be hard to determine which of these two forms is actualized.

Functional differences among some of these forms are also quite elusive. But we can pay attention to some crucial properties of these forms. Those variants that are associated with RPD with secondary EPD [i.e., (88.2), (89.2/3), (90.2), (91.2/3)] are assumed to have some emphatic/contrastive effect, thus they bear some pragmatic presuppositions. To illustrate this point by way of an example with a proper context, consider (91.3) in the following discourse:

(92) 1 John-wa Mary-ga yuBIWA-O kaTTA-to TOm-ni iWANAkatta 'John did not tell Tom that Mary bought a ring'

2 iYARINGU-O kaTTA TO-mo iWANAkatta earling bought said-not

'Nor that she bought an earling'

3 toKEE-O kaTTA TO-mo iWANAkatta watch bought said-not

'Nor that she bought a watch'

4 Kekkyoku, 
Prosody and the Syntax of Indeterminates

\author{
'After all' \\ 5 John-wa Mary-ga naNI-O kaTTA TO-mo TOm-ni iWANAkatta. \\ what bought said-not \\ 'John did not tell Tom that she bought anything'
}

In this context, (92.5) [= (91.3)] may indeed be taken as a kind of meta-statement: it does not simply state that, of anything, John did not tell Tom that Mary bought them, but at the same time it summarizes what has preceded it in the discourse, which serves the role of a pragmatic presupposition for (91.3) in the context.

In contrast, those forms with RPD without secondary EPD [(i.e., (88.1) - (91.1)] are assumed to be unmarked; grammatically they are free from any pragmatic presupposition; they could be associated with, but do not entail the existence of, such a pragmatic presupposition as indicated in the discourse of (92).

So far, we have kept the second indeterminates in (88)-(89) invariant as daRE-NI$M O$. According to KDA-RI, we may substitute DAre-ni-mo for it. Corresponding to each of the forms in (88) and (89), we have a variation with DAre-ni-mo, a universal quantifier:

(93) 1 John-wa Mary-ga naNI-O KATTA-TO-MO DAre-ni-mo iWANAkatta

2 John-wa Mary-ga naNI-O kaTTA-to-mo DAre-ni-mo iWANAkatta

3 John-wa Mary-ga NAni-o kaTTA-to-mo DAre-ni-mo iWANAkatta

(94) 1 John-wa Mary-ga naNI-O KATTA TO-MO DAre-ni-mo iWANAkatta

2 John-wa Mary-ga naNI-O KATTA TO-mo DAre-ni-mo iWANAkatta

3 John-wa Mary-ga naNI-O kaTTA TO-mo DAre-ni-mo iWANAkatta

4 John-wa Mary-ga NAni-o kaTTA TO-mo DAre-ni-mo iWANAkatta

However, I feel somewhat uncomfortable with (93.1-2) and (94.1-3). In these forms, DAreni-mo must be interpreted as a universal quantifier and must take with scope wider than negation, but at the same time naNI, which precedes DAre, must take narrower scope than negation. This conflict perhaps causes processing difficulty. If DAre-ni-mo is put before the to-clause, I get sentences that sound much better than (93.1-2) and (94.1-3):

(93')1 John-wa DAre-ni-mo Mary-ga naNI-O KATTA-TO-MO iWANAkatta

2 John-wa DAre-ni-mo Mary-ga naNI-O kaTTA-to-mo iWANAkatta

3 John-wa DAre-ni-mo Mary-ga NAni-o kaTTA-to-mo iWANAkatta

(94') 1 John-wa DAre-ni-mo Mary-ga naNI-O KATTA TO-MO iWANAkatta

2 John-wa DAre-ni-mo Mary-ga naNI-O KATTA TO-mo iWANAkatta

3 John-wa DAre-ni-mo Mary-ga naNI-O kaTTA TO-mo iWANAkatta

4 John-wa DAre-ni-mo Mary-ga NAni-o kaTTA TO-mo iWANAkatta

To sum up, with bridge verbs, the KDA-RI analysis works well; we have confirmed that we have no island problem with negative concord indeterminates as we do not with interrogative indeterminates. 


\subsubsection{Subordinate clauses with kadooka}

Next, we consider the case with a verb that selects a kadooka complement. With piedpiping taken into consideration, we would expect the following paradigm corresponding to $(50 \mathrm{a} / \mathrm{b})$ for the negative concord construction:

(95) a. $\diamond$ John-wa [Mary-ga nani-o katta -kadooka]-mo dare-ni-mo kikanakatta

anything bought whether anyone ask-neg-past

\$ohn did not ask anyone whether Mary bought anything'

'Of anything, John did not ask anyone whether Mary bought it'

b. $\searrow$ John-wa [Mary-ga nani-o katta-kadooka]-mo Tom-ni kikanakatta

anything bought whether Tom ask-neg-past

४ John did not ask to Tom whehter Mary bought anything'

'Of anything, John did not ask Tom whether Mary bought it'

I put $\diamond$ here to indicate that for the moment I proceed in suspending the grammaticality judgments on these forms. If kadooka does not have an "island effect" for negative polarity indeterminates as well, (95)b should be acceptable. For that matter, the island effect could be tested with simpler forms:

(96) $\diamond$ John-wa Mary-ga nani-o katta -kadooka-mo kikanakatta anything bought whether ask-neg-past

'Of anyting, John did not ask pro whether Mary bought it'

(97) $\diamond$ John-wa Mary-ga nani-o katta-kadooka-mo oboete-inai anything remember be-neg

'Of anything, John does not remember whether Mary bought it'

(96) does not contain an overt indirect object; the indirect object is understood. (97) has a predicate that does not select indirect object.

Let us consider (97). The underlying lexical accents in (97) must be shown. The word kadooka is a Complementizer and a unit in syntax but morphologically it is analyzed as follows:

(98) > ka' \#/>do'o \#/>ka'.

From (98), we can determine four prosodic alternants for the phrase katta-ka-doo-ka-mo:

(99) a. kat $>\mathrm{ta}^{\prime}>\mathrm{ka} \mathrm{a}^{\prime}>$ do'o $>\mathrm{ka}^{\prime}>\mathrm{mo}=\mathrm{kaTTA}-\mathrm{ka}$-doo-ka-mo

b. kat $>\mathrm{ta}^{\prime}>\mathrm{ka}$ ' \#do'o $>\mathrm{ka} \mathrm{a}^{\prime}>\mathrm{mo}=\mathrm{kaTTA}-\mathrm{ka}$ DOo-ka-mo

c. kat $>\mathrm{ta}^{\prime}>\mathrm{ka}^{\prime}>$ do'o \#ka'>mo = kaTTA-ka-doo KA-mo

d. kat $>\mathrm{ta}^{\prime}>\mathrm{ka}$ ' \#do'o \#ka' >mo = kaTTA-ka DOo KA-mo

The morphological structure of oboete-inai is 
For the interest of space, however, it suffices for our purposes to consider only one prosodic possibility: oBOete-inai. We can apply KDA-RI to (97) with each of the alternants in (99) and get the following forms:

(101) a1 $\diamond$ John-wa Mary-ga naNI-O KATTA-KA-DOO-KA-MO oBOete-inai

a2 $\diamond$ John-wa Mary-ga naNI- $O$ kaTTA-ka-doo-ka-mo oBOete-inai

a3 $\searrow$ John-wa Mary-ga NAni-o kaTTA-ka-doo-ka-mo oBOete-inai

b1 John-wa Mary-ga naNI-O KATTA-KA DOO-KA-MO oBOete -inai

b2 $\diamond$ John-wa Mary-ga naNI-O KATTA-KA DOo-ka-mo oBOete-inai

b3 $\diamond$ John-wa Mary-ga naNI-O kaTTA-ka DOo-ka-mo oBOete-inai

b4 $\searrow$ John-wa Mary-ga NAni-o kaTTA-ka DOo-ka-mo oBOete-inai

c1 $\backslash$ John-wa Mary-ga naNI-O KATTA KA-DOO-KA-MO oBOete-inai

c2 $\diamond$ John-wa Mary-ga naNI-O KATTA-KA-DOO KA-mo oBOete-inai

c3 $\diamond$ John-wa Mary-ga naNI-O kaTTA-ka-doo KA-mo oBOete-inai

c4 $\searrow$ John-wa Mary-ga NAni-o kaTTA-ka-doo KA-mo oBOete-inai

d1 $\$ John-wa Mary-ga naNI-O KATTA-KA DOO KA-MO oBOete-inai

d2 $\diamond$ John-wa Mary-ga naNI-O KATTA-KA DOO KA-mo oBOete-inai [=c2]

d3 $\diamond$ John-wa Mary-ga naNI-O KATTA-KA DOo KA-mo oBOete-inai

d4 $\diamond$ John-wa Mary-ga naNI-O kaTTA-ka DOo KA-mo oBOete-inai

d5 $\searrow$ John-wa Mary-ga NAni-o kaTTA-ka DOo KA-mo oBOete-inai

(101a1), (101b1), (101c1) and (101d1) are phonetically identical; they are associated with RPD without secondary EPD. (101c2) and (101d2) are also identical. For each of (101a)(101d), the last entry is associated with EPD with nani interpreted as a universal quantifier. The rest have RPD with secondary EPD. I would say that the 16 forms in (101) are all "morphologically" well-formed, that is, they sound like good Japanese sentence forms if one does not attend to what it might mean.

We can enumerate all the possible prosodic patterns for $(95 \mathrm{a} / \mathrm{b})$ in a similar manner. For (95a), we will have altogether 32 entries, 16 with the indirect object given as daRE-NI$M O$, and 16 as DAre-ni-mo. For each of these groups the form with RPD without secondary EPD is counted four times, just as in (101); there are 4 forms associated with EPD, with nani taken as a universal quantifier; the remaining eight have RPD with secondary EPD, of which two are identical. All these forms, I again maintain, are morphologically well-formed. In all, then, (95a) is prosodically 26 ways ambiguous. For (95b), we have essentially the same paradigm as for (101); one with RPD without secondary EPD, seven with RPD with secondary EPD, four with EPD. Of these alternative forms for (97) and (95a/b), it would be hard to differentiate some from others if they are given with the natural flow of speech. But I maintain that they can be distinguished from each other in introspection, or even in speech form, if we pronounce them deliberately enough to distinguish them.

It is quite difficult to make grammaticality judgments on all of these forms. Nonetheless, we can try to make some sense out of as much judgment as we can make on 


\section{S.-Y. Kuroda}

these forms. First of all, I would tentatively rule out as ungrammatical all the forms with EPD where nani is taken as universal NAni:

(102) *John-wa Mary-ga NAni-o kaTTA-ka-doo-ka-mo oBOete-inai

(103) *John-wa Mary-ga NAni-o kaTTA-ka-doo-ka-mo daRE-NI-MO kiKANAkatta

*John-wa Mary-ga NAni-o kaTTA-ka-doo-ka-mo DAre-ni-mo kiKANAkatta

I would also rule out tentatively as unacceptable the forms associated with RPD without secondary EPD, although relevant judgments are somewhat elusive:

*John-wa Mary-ga naNI-O KATTA-KA-DOO-KA-MO oBOete-inai

(105) *John-wa Mary-ga naNI-O KATTA-KA-DOO-KA-MO daRE-NI-MO kiKANAkatta

(106) *John-wa Mary-ga naNI-O KATTA-KA-DOO-KA-MO DAre-ni-mo kiKANAkatta

(107) *John-wa Mary-ga naNI-O KATTA-KA-DOO-KA-MO Tom-ni kiKANAkatta

I will return to discuss the judgment on these forms shortly.

The remaining are the forms with RPD with secondary EPD. They come in a great variety, as the locus of emphatic stress shifts. Judgments over forms of this category are inevitably subtle. Nonetheless, some forms seem to be susceptible to more secure judgments than others. Consider (101d4). This form seems quite adequate in a discourse context similar to (92) such as follows:

(108) John-wa Mary-ga TAko-o kaTTA-ka DOo-ka oBOete-inai octopus bought whether rememver is-neg

'John does not remember whether Mary bought octopus. iKA-O kaTTA-ka DOo KA-mo oBOete-inai squid bought whether remember is-neg 'Nor whether she bought squid or not' saBA-O kaTTA-ka DOo KA-mo oBOete-inai mackerel bought whether remember is-neg

Kekkyoku 'Nor whether she bought mackerel or not'

'After all,'

John-wa Mary-ga naNI-O kaTTA ka DOo KA-mo oBOete-inai [=(101d4)]

anything bought whether remember is-neg

'of anything, John does not remember whether Mary bought it or not.'

In this context, as in (92), (101d4) counts as a meta-statement which summarizes what has preceded it in the discourse. Here a pragmatic, contextual presupposition is given to (101d4) by the statements that precede it. An emphatic focus is put on kaTTA-ka, which is a common predicate that is attributed to the contrastive objects, octopus, squid and mackerel. The choosing of the form kaTTA-ka DOo KA-mo where KA-mo is 
morphologically separated implies putting some degree of emphasis on KA-mo. But the acceptability seems to be further enhanced if emphatic stress is also put on KA-mo:

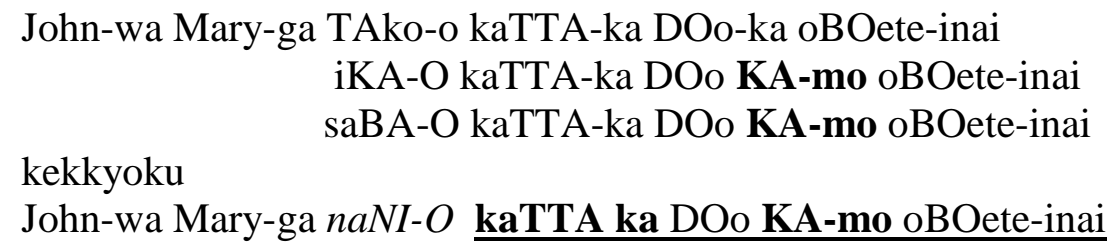

This form with more emphatic stress is possible on the basis of (101d4), because a "curtailed" lexical accent can be revoked, or even enhanced, to start a new token of Short EPD.

For reasons I am not going to elaborate for the sake of space, (101d4) is, I think, about the most suited for us to concoct a suitable context for enhanced acceptability. For other forms with secondary EPD in (101) it is not so easy to construct contexts in which the head of the secondary EPD gets contrasted. But it seems sensible to assume that forms associated with secondary EPD are all acceptable if proper contexts can be provided. For this reason, I decide to count them as theoretically grammatical.

I make the same assumption for forms related to (95a/b): the forms with secondary EPD are acceptable if they are provided proper contexts. For the benefit of the reader I will display all such forms related to (95a) on the model of (101):

a2 J-wa M-ga naNI-O kaTTA-ka-doo-ka-mo daRE-NI-MO kiKANAkatta

b2 J-wa M-ga naNI-O KATTA-KA DOo-ka-mo daRE-NI-MO kiKANAkatta

b3 J-wa M-ga naNI-O kaTTA-ka DOo-ka-mo daRE-NI-MO kiKANAkatta

c2 J-wa M-ga naNI-O KATTA-KA-DOO KA-mo daRE-NI-MO kiKANAkatta

c3 J-wa M-ga naNI-O kaTTA-ka-doo KA-mo daRE-NI-MO kiKANAkatta

d2 J-wa M-ga naNI-O KATTA-KA-DOO KA-mo daRE-NI-MO kiKANAkatta [=c2]

d3 J-wa M-ga naNI-O KATTA-KA DOo KA-mo daRE-NI-MO kiKANAkatta

d4 J-wa M-ga naNI-O kaTTA-ka DOo KA-mo daRE-NI-MO kiKANAkatta

(110) lists forms where the indirect object dare-ni-mo is actualized as daRE-NI-MO. If we substitute DAre-ni-mo for daRE-NI-MO, DAre-ni-mo must be preposed, in order to resolve the conflict between the narrow scope of naNI and the wide scope of DAre, as we have seen above with (94)-(95). By analogy with (108), we can concoct a discourse context where (110d4) would be appropriate:

John-wa Mary-ga TAko-o kaTTA-ka DOo-ka daRE-NI-MO kiKANAkatta octopus bought whether anyone ask-neg-past

'John does not ask anyone whether Mary bought octopus or not.

iKA-O kaTTA-ka DOo KA-mo daRE-NI-MO kiKANAkatta

squid bought whether anyone ask-neg-past

'Nor whether she bought squid or not' 
Kekkyoku

'After all,'

John-wa Mary-ga naNI-O kaTTA-ka DOo KA-mo daRE-NI-MO kiKANAkatta

anything bought whether anyone ask-neg-past

'of anything, J does not ask anyone whether M bought it or not.'

Let me summarize: I have decided that the forms with RPD accompanied by secondary EPD are acceptable; on the other hand, I have decided tentatively that all the other forms, that is, those with RPD without secondary EPD or those with universal quantifier NAni instead of negative concord naNI are ungrammatical.

We now proceed, so to speak, to the heart of a matter. What is remarkable is that curiously if we drop the pied-piping mo after kadooka in (105), we get an acceptable form:

(112) John-wa Mary-ga naNI-O KATTA-KA-DOO-KA daRE-NI-MO kiKANAkatta anything bought whether ask-neg-past

Dohn did not ask anyone that Mary bought anything'

'Of anything, John did not ask anyone whether Mary bought it or not'

We can have secondary EPD imposed on RPD without changing grammaticality of (112); that is, in effect, we may also drop mo after kadooka in (110):

(113) a2 J-wa M-ga naNI-O kaTTA-ka-doo-ka daRE-NI-MO kiKANAkatta

b2 J-wa M-ga naNI-O KATTA-KA DOo-ka daRE-NI-MO kiKANAkatta

b3 J-wa M-ga naNI-O kaTTA-ka DOo-ka daRE-NI-MO kiKANAkatta

c2 J-wa M-ga naNI-O KATTA-KA-DOO KA daRE-NI-MO kiKANAkatta

c3 J-wa M-ga naNI-O kaTTA-ka-doo KA daRE-NI-MO kiKANAkatta

d2 J-wa M-ga naNI-O KATTA-KA-DOO KA daRE-NI-MO kiKANAkatta [=c2]

d3 J-wa M-ga $n a N$ - $O$ KATTA-KA DOo KA daRE-NI-MO kiKANAkatta

d4 J-wa M-ga naNI-O kaTTA-ka DOo KA $d a R E-N I-M O \underline{\text { kiKANAkatta }}$

We do not get the same effect with (104) or (107):

(114) *J-wa M-ga naNI-O KATTA-KA-DOO-KA oBOete-inai

(115) *John-wa Mary-ga naNI-O KATTA-KA-DOO-KA Tom-ni kiKANAkatta

Nor with (106), either; nor does the preposing of DAre help:

(116) *John-wa Mary-ga naNI-O KATTA-KA-DOO-KA DAre-ni-mo kiKANAkatta

(117) *John-wa DAre-ni-mo Mary-ga naNI-O KATTA-KA-DOO-KA kiKANAkatta. 
Coupling (112) with (115) we obtain a Watanabe type of paradigm, a minimal pair contrast:

$$
\begin{aligned}
& \text { a. John-wa Mary-ga naNI-O KATTA-KA-DOO-KA daRE-NI-MO kiKANAkatta } \\
& \text { anything bought whether anyone ask-neg-past } \\
& \text { John did not ask anyone that Mary bought anything' } \\
& \text { 'Of anything, John did not ask anybody whether Mary bought it or not' } \\
& \text { b. *John-wa Mary-ga naNI-O KATTA-KA-DOO-KA Tom-ni kiKANAkatta } \\
& \text { anything bought whether Tom ask-neg-past } \\
& \text { OJohn did not ask anyone that Mary bought anything' } \\
& \text { 'Of anything, John did not ask Tom whether Mary bought it or not' }
\end{aligned}
$$

The apparent violation of an island in (118) is rescued by an extra indeterminate matrix argument in (118a). The crucial point is that the presence of an indeterminate matrix argument, daRE-NI-MO, and the absence of mo after kadooka save (118a) from an island effect. In contrast, (118b) has no occurrence of negative concord Q-particle mo that is bound by NEG, and the ungrammaticality of (118b) can be attributed to the absence of mo. In my judgment, though it is subtle, the addition of mo after kadooka does not save (118b); mo cannot pied pipe kadooka. In order to indicate these factors, a Watanabe paradigm (118) should be revised as follows, indicating how the presence or absence of mo affects the grammaticality contrast:

\section{a. John-wa Mary-ga naNI-O KATTA-KA-DOO-KA (*MO) daRE-NI-MO kiKANAkatta \\ b. *John-wa Mary-ga naNI-O KATTA-KA-DOO-KA-(MO) Tom-ni kiKANAkatta}

Note, incidentally, that if we impose secondary EPD on naNI-O KATTA-KA-DOO$K A$ in (119), the paradigm changes and its significance becomes quite different. For example, with katta-ka-doo-ka analyzed as kat $>\mathrm{ta}^{\prime}>\mathrm{ka}^{\prime}>\mathrm{do}^{\prime} \mathrm{o}$ \#ka' $>\mathrm{mo}=\mathrm{kaTTA}-\mathrm{ka}-\mathrm{doo}$ KA-mo, we get the following pair from (119):

\section{a. J-wa M-ga naNI-O kaTTA-ka-doo KA-(mo) daRE-NI-MO kiKANAkatta $[=(110 \mathrm{c} 3),(113 \mathrm{c} 3)]$ \\ b. J-wa M-ga naNI-O kaTTA-ka-doo KA-*(mo) Tom-ni kiKANAkatta}

As we have determined above, secondary EPD overrides the island effect. Hence, with the imposition of secondary EPD, a subjacency violation is not an issue any more in (120). Rather, (120) shows the point that a negative concord indeterminate requires the presence of at least one mo.

Admittedly, the facts presented above according to my judgments are quite abstruse. In order to facilitate for the native speaker to measure their own acceptability judgments on relevant forms against mine and for them to rule on the grammaticality of pertinent constructions, let me add one more set of examples of the same type as above. Consider 


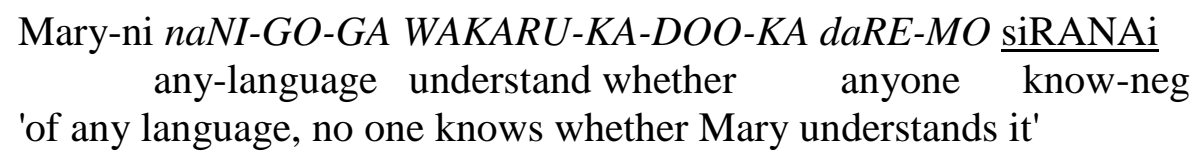

This form has two negative concord RI terms, naNI-GO 'what language' and daRE 'anyone' The former is inside a kadooka clause. Q-particle mo is not attached to kadooka. Both RI terms are associated with RPD without secondary EPD: naNI-GO-GA WAKARU-KA$D O O-K A$ and daRE-MO. (121) is acceptable. So are the forms obtained by imposing secondary EPD on the first RPD:

1 Mary-ni naNI-GO-GA WAKARU-KA DOO KA daRE MO $\underline{\text { siRANAi }}$

2 Mary-ni naNI-GO-GA WAKARU-KA DOo-ka daR-MO $\underline{\text { siRANAi }}$

3 Mary-ni naNI-GO-GA waKAru-ka DOo-ka daRE-MO $\underline{\text { siRANAi }}$

However, if we affix mo to kadooka and pied-pipe naNI-GO in the embedded clause in (121), we get ungrammatical forms:

(123) *Mary ni naNI-GO-GA WAKARU-KA DOO-KA-MO daRE-MO $\underline{\text { siRANAi }}$

In contrast, if we do the same to (122.1-3), we get forms presumably acceptable if given in contexts with adequate pragmatic presuppositions:

(124) 1 Mary-ni naNI-GO-GA WAKARU-KA DOO KA-mo daRE-MO $\underline{\text { SiRANAi }}$

2 Mary-ni naNI-GO-GA WAKARU-KA DOo-ka-mo daRE-MO $\underline{\text { SiRANAi }}$

3 Mary-ni naNI-GO-GA waKAru ka DOo-ka-mo daRE-MO $\underline{\text { siRANAi. }}$

We obtain the Watanabe paradigm without mo after kadooka in the a-version:

(125) a. Mary-ni naNI-GO-GA WAKARU-KA-DOO-KA (*-MO) daRE MO SiRANAi

b. *Mary-ni naNI-GO-GA WAKARU-KA-DOO-KA (-MO) John-ga/wa siRANAi question:

Let me add a couple of more examples just to illustrate the Watanabe paradigm in
a. daRE-GA SIKEN-NI UKARU-KA-DOO-KA (*MO) daRE-NI-MO anyone exam pass whether anyone waKARAnai understand 'of anyone, no one can tell whether they will pass the exam or not'

b *daRE-GA SIKEN-NI UKARU-KA-DOO-KA(-MO) JOHn-ni (wa) waKARAnai exam pass whether understand 'of anyone, John cannot tell whether they will pass the exam'
a. daRE-GA UKARU KA DOO KA (*MO) daRE MO ki-NI-SI-TE iNAi anyone pass whether anyone mind do is-neg 'of anyone, no one doesn't care if they pass (the exam)'
b. *daRE-GA UKARU KA DOO KA (MO) JOHn-wa/ga ki-NI-SI-TE iNAi 
Prosody and the Syntax of Indeterminates

anyone pass whether mind do is-neg
'of anyone, John doesn't care if they pass (the exam)'

Let me summarize the significance of our findings. First of all, the prosodic patterns associated with negative concord RIs can be determined by the revised KitagawaDeguchi Analysis, KDA-RI. We have confirmed that we need to distinguish between simple RPD and RPD accompanied by secondary EPD. This distinction, I maintain, is relevant to determining whether kadooka introduces island effects for negative concord indeterminates inside kadooka clauses. It turned out that if such a negative concord RI is associated with simple RPD an island effect arises, but it does not, if a negative concord indeterminate is associated with RPD accompanied by secondary EPD. However, in the former case, the island effect is removed if, first, the pied-piping mo attached to kadooka is removed and if, secondly, the kadooka clause is followed by another RI which is a matrix argument. This second condition reminds us of the original Watanabe paradigm.

Put succinctly by ignoring complicating details, we might simply state that the Watanabe phenomenon obtains with the negative concord indeterminates if we do not pied-pipe kadooka and if we keep prosody straight, i.e., keep RPD simple and pure.

Recall that when we encountered examples with pied-piped kadooka like (104) and (105), I tentatively ruled them out as ungrammatical. But in the Watanabe paradigm, they contrast sharply, on the one hand, with the forms without pied-piping $m o$, and on the other, with the forms without matrix negative concord indeterminates. Clear and distinct judgments are hard to obtain on examples such as (104) and (105) by pure intuition. Putting them in a proper perspective, we determine that they are ungrammatical. The detailed investigation of possible prosodic patterns associated with RIs helps clear "noises" that can intervene in our acceptability judgment: secondary EPD lets Q-particle mo piedpipe kadooka and let RIs override wh-island effects.

To give an exact syntactic account to the above findings is outside of the scope of this paper, but let me add here a few speculative thoughts on this matter. Note that the particle $m o$, besides its function in negative concord, has a basic function as a focus marker with the connotation similar to also. Recall the discourse contexts I concocted above in order to make indeterminates inside kadooka clauses override an island constraint. The problematic forms are preceded by forms that contain a kadooka-mo clause with no indeterminate in it. For example, in (111) iKA-O kaTTA-ka DOo-KA-mo 'nor whether she bought squid or not', saBA-O kaTTA-ka DOo KA-mo 'nor whether she bought mackerel or not' precedes naNI $O \underline{\boldsymbol{k a T T A}-\boldsymbol{k} \boldsymbol{a}} \underline{\mathrm{DOO}} \underline{K A-m o}$. The particle mo functions as a focus marker, not as an indicator of negative concord, in these phrases.

I suggest, first, that syntactically mo behaves differently with these two different functions. Secondly, the mo that follows naNI-O kaTTA-ka DOo KA-mo in the context of (111) is an instance of a focus marker, not a negative concord indicator per se. The accent patterns corroborate this assumption. Finally, I suggest that the negative concord mo cannot attach to kadooka but the focus marker mo can. This difference may arise from the difference in possible "landing sites" for the focus and the negative concord mo. 
Finally, let me return to the forms with universal indeterminates like (102)-(103), which I repeat:

(102) *John-wa Mary-ga NAni-o kaTTA-ka-doo-ka-mo oBOete-inai

(103) *John-wa Mary-ga NAni-o kaTTA-ka-doo-ka-mo daRE-NI-MO kiKANAkatta

*John-wa Mary-ga NAni-o kaTTA-ka-doo-ka-mo DAre-ni-mo kiKANAkatta

Recall we have here universal FI NAni instead of RI naNI. If we have the same Watanabe phenomenon with $N A n i$ as with $n a N I$ we must have the following paradigms; note that we have negative concord daRE in (128) and universal DAre in (129):

(128) a. John-wa Mary-ga NAni-o kaTTA-ka-doo-ka (*-mo) daRE-NI-MO kiKANAkatta b. *John-wa Mary-ga NAni-o kaTTA-ka-doo-ka (-mo) Tom-ni kiKANAkatta

(129) a. John-wa Mary-ga NAni-o kaTTA-ka-doo-ka (*mo) DAre-ni-mo kiKANAkatta b. *John-wa Mary-ga NAni-o kaTTA-ka-doo-ka (mo) Tom-ni kiKANAkatta

But it appears to my intuition that the forms with the pied-piping mo in both a and $b$ versions are more acceptable than the comparative forms in (119). We seem to have the following paradigm instead:

(130) a. John-wa Mary-ga NAni-o kaTTA-ka-doo-ka (mo) daRE-NI-MO kiKANAkatta

b. John-wa Mary-ga NAni-o kaTTA-ka-doo-ka *(mo) Tom-ni kiKANAkatta

(131) a. John-wa Mary-ga NAni-o kaTTA-ka-doo-ka (mo) DAre-ni-mo kiKANAkatta

b. John-wa Mary-ga NAni-o kaTTA-ka-doo-ka *(mo) Tom-ni kiKANAkatta

Now, if we follow the lines of thought above, we might conclude that mo functioning as the I-goal associated with universal indeterminates may not attach to kadooka as negative concord mo may not, and that the occurrences of mo after kadooka in these examples are the focus marker mo. This interpretation is possible. For, since NAni-o heads EPD, not RPD, and there is no secondary head inside the kadooka phrase in (130) or (131), we can interpret NAni-o itself as an emphatic focus. We thus seem to have an account of the paradigm illustrated by (128)-(129).

As a matter of fact, however, we should recognize two paradigms simultaneously; one as illustrated by (128)-(129) and the other by the following, slightly different from the one illustrated by (130)-(131):

(132) a. John-wa Mary-ga NAni-o kaTTA-ka-doo-ka *(-mo) daRE-NI-MO kiKANAkatta b. John-wa Mary-ga NAni-o kaTTA-ka-doo-ka *(-mo) Tom-ni kiKANAkatta

(133) a. John-wa Mary-ga NAni-o kaTTA-ka-doo-ka *(-mo) DAre-ni-mo kiKANAkatta

b. John-wa Mary-ga NAni-o kaTTA-ka-doo-ka *(-mo) Tom-ni kiKANAkatta 
The former is the paradigm we expect with mo after kadooka interpreted as the I-goal of universal FI indeterminates, and the latter is the one realized with mo as a focus marker. If we superimpose one on the other, we get (130)-(131).

The EPD phrase NAni-o kaTTA-ka-doo-ka *(-mo) may also take secondary EPD. For example, we could make $k a$ a secondary head. Then, we get only the paradigm that corresponds to (132)-(133), not the one corresponding to (128)-(129): we have

(134) a. John-wa Mary-ga NAni-o kaTTA-ka-doo KA *(-mo) daRE-NI-MO kiKANAkatta b. John-wa Mary-ga NAni-o kaTTA-ka-doo KA *(-mo) Tom-ni kiKANAkatta

(135) a. John-wa Mary-ga NAni-o kaTTA-ka-doo KA *(-mo) DAre-ni-mo kiKANAkatta b. John-wa Mary-ga NAni-o kaTTA-ka-doo KA*(-mo) Tom-ni kiKANAkatta

and, I believe, the following forms are unacceptable:

(136) * John-wa Mary-ga NAni-o kaTTA-ka-doo KA daRE-NI-MO kiKANAkatta

(137) * John-wa Mary-ga NAni-o kaTTA-ka-doo KA DAre-ni-mo kiKANAkatta

These observations corroborate the assumption that the mo after a kadooka clause with a FI indeterminate like $N A n i$ can in principle be either a I-goal marker or a focus particle; secondary EPD, however, resolves this ambiguity.

\section{The Watanabe paradigm regained}

Let me make this last concluding section somewhat autobiographical. I begin by repeating Watanabe's classical paradigm with his judgment:

(138) (Watanabe 1992:263)

a. John-wa [Mary-ga nani-o katta kadooa ] dare-ni tazuneta-no? what bought whether asked-CompWH

'What did John ask whom [ whether Mary bought t1 ]?'

b. ??John-wa [Mary-ga nani-o katta kadooka ] Tom-ni tazuneta-no? what bought whether asked-CompWH

'What did John ask Tom [ whether Mary bought t ]?'

In the preceding discussion, I have taken the b-sentence as grammatical, given proper prosody, following Kitagawa and Deguchi. In my earlier work, however, I followed Watanabe and took the b-sentence as ungrammatical. I thought then that sentences like $(138 b)$ and some other examples that apparently violate subjacency are not absolutely unacceptable. I had some apprehension to rule them out as ungrammatical. Nonetheless, I followed Watanabe and ruled them ungrammatical. ${ }^{9}$ There was a background for this

\footnotetext{
${ }^{9}$ Watanabe marked (135b) with two question marks; I marked similar sentences ?* in (Kuroda 1992) and * in (Kuroda 1997).
} 
decision. Root sentences are liable to "discourse noises" that affect acceptability judgments more than embedded ones. So I thought I should test the reality of the original Watanabe phenomenon inside subordinate clauses. For this purpose, I considered nominals that subcategorize for indirect questions such as mondai 'question/problem' and situmon 'question/query'. The outcome , I thought, is quite clear: Watanabe's judgment is upheld.

To follow this line of thought, let us first observe the following non-problematic examples to set a base line:

(139) John-ga [Mary-ga nani-o katta -to] Tom-ni itta-ka-to yuu mondai what bought that said problem

'the problem as to what John told Tom Mary bought'

(140) John-ga [Mary-ga nani-o katta-to] Tom-ni itta-ka-to yuu situmon 'the question as to what John told Tom Mary bought'

(141) John-ga [Mary-ga hon-o katta kadooka ] dare-ni kiita-ka-to yuu mondai book bought whether ask problem 'the problem as to whom John asked whether Mary bought a book'

(142) John-ga [Mary-ga hon-o katta kadooka ] dare-ni kiita-ka-to yuu situmon 'the question as to whom John asked whether Mary bought a book'

Now we substitute nani for hon:

a. John-ga Mary-ga nani-o katta kadooka dare-ni kiita-ka-to yuu mondai what bought whether who asked-

'the problem as to what John asked whom whether Mary bought?'

b. *John-ga Mary-ga nani-o katta kadooka Tom-ni kiita-ka-to yuu mondai what bought whether Tom

'the problem as to what John asked Tom whether Mary bought'

(144) a. John-ga Mary-ga nani-o katta kadooka DAre-ni kiita-ka-to yuu situmon what bought whether who asked'the question as to what John asked whom whether Mary bought?'

b. *John-ga Mary-ga nani-o katta kadooka Tom-ni kiita-ka-to yuu situmon what bought whether Tom

'the quesiton as to what John asked Tom whether Mary bought'

I had firmer judgments on the b-sentences of this type: I judged that Watanabe's grammaticality judgment must be accepted.

Now that we have Kitagawa and Deguchi's work, one might say in retrospect that I did not give proper prosody to b-sentences in the Watanabe paradigm and failed to accept the starred forms. But I don't think this is not a good response. Kitagawa and Deguchi's claim, as I take it, is that EPD is proper prosody for wh-questions, including those like (138a/b), and here "proper" means "natural," not "careful," or "deliberate." 
I am willing to admit that it would not be impossible to put heavy emphatic stress on NAni-o in $(143 b) /(144 b)$ and accept $(143 b) /(144 b)$, but I would not take it as "natural prosody." A remark may be in order to substantiate this point. To be sure, one can put emphatic stress on NAni in (143b)/(144b). Emphatic stress, however, is a matter of degree. Whether one can put emphatic stress on nani is not so much of a problem. The point, rather, is another factor that characterizes EPD that accompanies the interrogative sentence: the raising of pitch at the end of the sentence. The natural prosody that accompanies the embedded question lacks this feature. Thus, the last part of (143a) is pronounced smoothly like kiITA ka to yuU moNDAI, without noticeable raising of pitch at $k a$.

In order to get "proper" prosody for accepting (143b)/(144b), if we can at all, not only do we put emphatic stress or pitch on nani, but also we need to put extra heavy stress on $k a$, possibly with an extra pause after it:

b' John-ga Mary-ga NAni-o katta kadooka Tom-ni kiita-KA // to yuu mondai what bought whether Tom

'the quesiton as to what John asked Tom whether Mary bought'

b' John-ga Mary-ga NAni-o katta kadooka Tom-ni kiita-KA // to yuu situmon what bought whether Tom

'the quesiton as to what John asked Tom whether Mary bought'

Lest the above story should sound like only an apologia for explaining how I was led (or, should I say, misled?) to Watanabe's judgment in my earlier work, let me note that real linguistic issues have yet to be spelled out. Let us grant for the sake of argument that Kitagawa and Deguchi's prosody cannot be imposed on subordinate sentences. Then, one might claim that the ungrammaticality of the b-forms in (143)/(144) is accounted for. But, then, we have to admit also that Kitagawa and Deguchi's prosody is irrelevant to the aforms; by assumption, we have to claim that we have accepted the a-forms in (143)-(144) without Kitagawa and Deguchi's prosody, without EPD. Thus, the claim that one cannot impose EPD on the b-forms cannot provide an account of the ungrammaticality of such forms. The fact of the matter is that EPD is a natural environment for independent whquestions, but it is not an indispensable ingredient of the syntax of wh-questions, let alone, of the syntax of indeterminate constructions. The Watanabe phenomenon, on the other hand, is rooted deeply in the syntax of indeterminate constructions in general.

Let us recapitulate and draw conclusions from what we have observed:

(I) EPD is not a required component of the syntax of interrogative clauses.

We derive (I) from the fact that EDP is not natural prosody for embedded questions. However,

(II) EPD is proper prosody for independent interrogative clauses.

(III) RPD is proper prosody for RI constructions. 
(IV) Secondary EPD may be imposed on RI constructions.

(III) and (IV) together imply that RPD is neutral prosody for RIs. That is, I hypothesize that RPD is default prosody for RIs and RPD with secondary EPD is marked prosody. This is an analytical hypothesis and independent of what prosody may or may not be found predominant in naturally recorded corpus. From these propositions, I draw the following conclusion on the Watanabe paradigm:

(V) The grammatical reality of the Watanabe phenomenon: The syntax of indeterminate constructions sanctions the generalized Watanabe paradigm for indeterminate constructions, and in particular, the original Watanabe paradigm for interrogative clauses.

(VI) EPD overrides the wh-island constraint.

As I have stated above I assume that (II) implies that EPD is natural prosody for independent wh-questions. (II) and (VI) together mean that the wh-island is "naturally" overridden in independent interrogative sentences; EPD is not an extra-device, not a metaor para-grammatical device, specifically to override the island. To wit, EPD makes the Watanabe paradigm an epi-phenomenon in natural environments for independent questions.

A syntactic account of the generalized Watanabe phenomenon must be worked out. But it is out of the scope of this paper. I have hypothesized that the Q-particles cannot attach to kadooka for pied-piping, but the homophonous focus particles can. Focus particles must be, and can be, licensed by EPD, either primary or secondary. These facts contribute to creating marked environments for non-interrogative indeterminates where the wh-island constraint can be overridden. The empirical data related to the Watanabe phenomenon is inevitably quite complex and confusing. ${ }^{10}$

Let me conclude this paper by stressing that the work on indeterminate constructions developed above, if it is on the right track, demonstrates that the study of prosody must be integral part of the research into the syntactic structures of language.

\section{References}

Kitagawa, Yoshihisa and Masanori Deguchi (2003) Prosody and syntactic analysis. ms. (v3.2) Indiana University, Bloomington, Indiana.

Kuroda, S.-Y. (1965) Generative grammatical studies in the Japanese language. Dissertation, MIT.

Kuroda, S.-Y. (1992) Nihongo seisei-bunpô no 30nen...Kojinteki kaisô (Thirty years of Japanese generative grammar. Personal reminiscences) Open Lecture, Linguistic Society of Japan. May, 1992.

Kuroda, S.-Y. (1997) Niohngo no gimon-shi to keiryô-shi (Japanese interrogatives and quantifiers.) Plenary talk, Eibungakkai, Sendai. May 25, 1997.

\footnotetext{
${ }^{10}$ Earlier attempts are found in Kuroda $(1992,1997,2003)$. Prosody was out of concern of these attempts.
} 
Prosody and the Syntax of Indeterminates

Kuroda, S.-Y. (2003) Handouts for the lectures given at University of Vitoria/Gasteisz.

Kuroda S.-Y. (forthcoming) On the syntax of Old Japanese. Proceedings of the Second Oxford-Kobe Linguistics Seminar: the History and Structure of Japanese.

Ishihara, Shinichiro (2003) Intonation and interface conditions. Dissertation, MIT.

McCawley, James D. (1968) The phonological component of a grammar of Japanese. Mouton, The Hague.

Watanabe, Akira (1992) Wh--in-situ, subjacency, and chain formation. MITWP 